\title{
Minimizing intraoperative hemodilution by use of a very low priming volume cardiopulmonary bypass in neonates with transposition of the great arteries
}

\author{
Matthias Redlin, MD, ${ }^{\mathrm{a}}$ Michael Huebler, MD, ${ }^{\mathrm{b}}$ Wolfgang Boettcher, ECCP, ${ }^{\mathrm{b}}$ Marian Kukucka, MD, ${ }^{\mathrm{a}}$ \\ Helge Schoenfeld, MD, ${ }^{\mathrm{c}}$ Roland Hetzer, MD, PhD, ${ }^{\mathrm{b}}$ and Helmut Habazettl, MD, PhD ${ }^{\mathrm{a}, \mathrm{d}}$
}

\begin{abstract}
Objective: Owing to the mismatch between cardiopulomary bypass priming volume and infants' blood volume, pediatric cardiac surgery is often associated with transfusion of homologous blood, which may increase the risk of perioperative complications. Here we report the impact of a very low volume $(95-110 \mathrm{~mL})$ cardiopulmonary bypass circuit during arterial switch operations in neonates with transposition of the great arteries on blood requirements, tissue oxygenation, and patient outcome.
\end{abstract}

\begin{abstract}
Methods: Twenty-three consecutively treated neonates aged 2 to 17 days were treated with the blood-sparing approach. Asanguineous priming was used in all cases and packed red blood cells were added when hemoglobin concentration decreased below $7 \mathrm{~g} / \mathrm{dL}$. Cerebral and lower body tissue oxygenation was monitored by nearinfrared spectroscopy. Intraoperative and postoperative transfusion, duration of ventilation and intensive care unit stay, wound infection, and 30-day mortality were assessed for patient outcome.
\end{abstract}

\begin{abstract}
Results: Intraoperative blood transfusion was necessary in 6 of 23 neonates. An additional 11 neonates received postoperative blood transfusions on the intensive care unit, leaving 6 infants who received no blood at all. Preoperative hemoglobin concentration was the only predictor for intraoperative transfusion requirement (11.6 \pm 0.9 and $13.3 \pm 0.4 \mathrm{~g} / \mathrm{dL}$ in infants with and without intraoperative transfusion, respectively). Despite marked differences in hemoglobin concentrations between infants with and without transfusion, regional tissue oxygenation increased in both groups during cardiopulmonary bypass and returned to baseline at the end of surgery. In-hospital patient outcome was similar in both groups.
\end{abstract}

Conclusions: Transfusion-free complex cardiac surgery can be achieved even in neonates without jeopardizing tissue oxygenation or patient safety. (J Thorac Cardiovasc Surg 2011;142:875-81)

During the past decades, improvements in cardiopulmonary bypass (CPB), surgical techniques, and intensive care have facilitated complex surgical procedures for the correction of congenital heart disease in even the smallest neonates. Although perioperative mortality is acceptably low in this special population, ${ }^{1,2}$ complications may be quite frequent. These include low output syndrome, arrhythmias, wound infection, inflammatory responses including sepsis, and, for years after surgery, neurologic abnormalities such as hypotonia, developmental delay, or attention deficit. The risk of complications may be increased by transfusion of homologous blood, ${ }^{3-8}$ which is required to maintain blood

\footnotetext{
From the Departments of Anesthesiology, ${ }^{\mathrm{a}}$ and Cardiothoracic and Vascular Surgery, ${ }^{\mathrm{b}}$ German Heart Institute, Berlin, Germany; the Institute of Transfusion Medicine, ${ }^{\mathrm{c}}$ Charité, University Medicine Berlin, Berlin, Germany; and the Department of Physiology, ${ }^{\mathrm{d}}$ Charité, University Medicine Berlin, Berlin, Germany.

Disclosures: Authors have nothing to disclose with regard to commercial support. M.R. and M.H. contributed equally to the study.

Received for publication Aug 26, 2010; revisions received Dec 17, 2010; accepted for publication Jan 26, 2011; available ahead of print May 13, 2011.

Address for reprints: Helmut Habazettl, MD, PhD, Institute of Physiology, Thielallee

71, 14195 Berlin, Germany (E-mail: helmut.habazettl@charite.de). $0022-5223 / \$ 36.00$

Copyright (c) 2011 by The American Association for Thoracic Surgery doi:10.1016/j.jtcvs.2011.01.068
}

hemoglobin concentration and hematocrit value within a range that guarantees sufficient oxygen transport capacity. Hemoglobin decreases owing to blood loss during surgery but mainly owing to the size of the $\mathrm{CPB}$ circuit's priming volume versus the infant's blood volume. Intraoperative blood loss can be minimized by optimizing the surgical technique to reduce or even avoid hemodilution. The effect of blood loss on hemoglobin may be partially equalized by using cell salvage techniques and retransfusing the red blood cells. Pivotal for limiting hemodilution is reduction of the priming volume of the CPB circuit. That may reduce not only anemia but also dilutional thrombocytopenia and dilution of plasmatic coagulation factors. ${ }^{9}$

In a joint effort of surgeons, perfusionists, and anesthesiologists, the $\mathrm{CPB}$ circuit used in pediatric cardiac surgery was redesigned to minimize the priming volume to 95 to $110 \mathrm{~mL},{ }^{10}$ and standard procedures were adapted with the goal of minimizing intraoperative hemodilution. The expected benefits of this approach are reduced need for transfusion of homologous blood products and better preservation of the coagulatory system. To recognize and avoid regional ischemia, we used near-infrared spectroscopy (NIRS) for monitoring of brain and lower body tissue 


\section{Abbreviations and Acronyms \\ $\mathrm{CPB}=$ cardiopulmonary bypass \\ ICU $=$ intensive care unit \\ NIRS $=$ near-infrared spectroscopy \\ $\mathrm{rSO}_{2}=$ regional tissue oxygenation \\ $\mathrm{TGA}=$ transposition of the great arteries}

oxygenation. ${ }^{11}$ Here we report our experience with this approach, its limitations, and its effects on tissue oxygenation and early patient outcome for a cohort of 23 neonates who were referred for surgical treatment of transposition of the great arteries (TGA) by the arterial switch operation.

\section{METHODS \\ Patients}

Between April 2007 and December 2009, 23 neonates were treated by the arterial switch operation for TGA with application of the "blood-sparing" approach. This included the use of the low priming volume CPB, avoidance of all additional hemodilution by minimizing blood sampling and by not using ultrafiltration, meticulous surgical technique to reduce bleeding, a transfusion trigger of hemoglobin concentration less than $7 \mathrm{~g} /$ $\mathrm{dL}$, and NIRS to ensure maintenance of cerebral and peripheral oxygenation. Ages ranged from 4 to 17 days, body weight was between 1.7 and $4.2 \mathrm{~kg}$, and body size between 43 and $55 \mathrm{~cm}$. All parents gave informed written consent for the surgical, anesthesiologic, and monitoring procedures. The retrospective data analysis was approved by the institutional review board.

\section{CPB and Surgery}

A CPB circuit was redesigned for use in neonates as described previously. ${ }^{10,12,13}$ A Stöckert S3 mast mounted console (Stöckert Instrumente $\mathrm{GmbH}$, Munich, Germany) was modified by shortening as much as possible all tubing connections. All tubings were 3/16-inch internal diameter except the arterial pump boot (1/4-inch) and suction lines (1/8inch). Low prime oxygenator (KIDS D100, Sorin, Mirandola, Italy) and arterial line filter (D130, Sorin) were used. Both for increase of venous return and for suction lines, roller pump suction heads were used. This modified system has a total priming volume of $110 \mathrm{~mL}$, which was further reduced to $95 \mathrm{~mL}$ for neonates of less than 3-kg body weight by using 3/16-inch internal diameter tubing for the arterial pump boot.

Asanguineous priming of the $\mathrm{CPB}$ was used in all patients. Immediately after mixing of the priming volume with the patients' blood, hemoglobin concentrations were assessed and packed red blood cells were added when the transfusion trigger of hemoglobin less than $7 \mathrm{~g} / \mathrm{dL}$ was reached. Antifibrinolysis was achieved by infusing $10 \mathrm{mg} \cdot \mathrm{kg}^{-1} \cdot \mathrm{h}^{-1}$ of tranexamic acid. During CPB, hypothermia to $26^{\circ} \mathrm{C}$ to $28^{\circ} \mathrm{C}$ was induced.

TGA was corrected by arterial switch. In addition, a ventricular septal defect was closed in 2 cases, the arterial duct ligated in 2 cases, and a hypoplastic aortic arch was reconstructed in 1 case.

\section{Monitoring}

Heart rate, arterial and central venous pressure, and temperatures were continuously monitored and data were read out at the times of blood gas analyses. Arterial blood gases were drawn and analyzed (Rapidlab 865; Siemens Healthcare Diagnostics, Inc, Deerfield, Ill) before surgery (preop), after the onset of CPB (CPB start), at 15-minute intervals during CPB (CPB mid), briefly before termination of CPB (CPB end), and during chest clo- sure (post-CPB). Central venous blood was analyzed during chest opening (pre-CPB) and after surgery (postop).

\section{NIRS}

A near-infrared spectrometer (NIRO-200; Hamamatsu Photonics KK, Hamamatsu City, Japan) equipped with 2 independent emitter-sensor pairs, each with a spatial separation of $4 \mathrm{~cm}$, was used. One pair of optodes was placed noninvasively on the patient's forehead for monitoring of brain oxygenation, and the second one was placed on the right calf for monitoring of lower body tissue oxygenation. Light was generated by 3 pulsed laser diodes at wavelengths of 775,810 , and $850 \mathrm{~nm}$ and emitted into the tissue through the source optode. Backscattered light from the tissue was collected by the detection probe equipped with a dual-segmented photodiode chip. With the spatially resolved spectroscopy method, regional tissue oxygenation $\left(\mathrm{rSO}_{2}\right)$ was calculated. ${ }^{14,15}$

\section{Statistics}

Patient characteristics and outcome data were compared between groups by the $t$ test for normally distributed data and by the MannWhitney test for intensive care unit (ICU) stay and ventilation. Incidence of postoperative transfusion, wound infection, and mortality was analyzed by Fisher's exact test. The time course of perioperative parameters was analyzed by repeated measures analysis of variance followed by Holm-Sidak post hoc analyses.

\section{RESULTS}

Initial priming without blood was attempted in all 23 cases. In 6 cases, between 50 and $125 \mathrm{~mL}$ (mean, $97 \pm 11$ $\mathrm{mL}$ ) of packed red blood cells were transfused during the procedure because the transfusion trigger of a hemoglobin level less than $7.0 \mathrm{~g} / \mathrm{dL}$ was met. In 3 cases, 50 to $70 \mathrm{~mL}$ of fresh frozen plasma was additionally transfused. In 17 neonates surgery could be completed without transfusion of any homologous blood products. Thus, 1 group of neonates (with blood, $n=6$ ) received intraoperative blood transfusion whereas the other group (without blood, $\mathrm{n}=17$ ) did not. The 2 groups did not differ in age, size, or body weight (Table 1). All 6 neonates (100\%) from the transfused group and 11 neonates $(65 \%)$ from the group without blood received transfusion of blood products on the pediatric ICU (for details see Table 2) resulting in 6 patients who received intraoperative and postoperative transfusion, 11 patients without intraoperative but with postoperative transfusion, and 6 patients who did not receive any homologous blood products. Patient outcome as assessed by duration of ventilation, ICU stay, the rate of wound infection, mortality, or inflammatory response (peak C-reactive protein) was similar among groups (Tables 1 and 2).

Preoperative hemoglobin was higher in the group without blood $(13.3 \pm 0.4 \mathrm{~g} / \mathrm{dL})$ than in the neonates who received blood transfusion $(11.6 \pm 0.9 \mathrm{~g} / \mathrm{dL})$ and decreased to, respectively, $9.1 \pm 0.3$ and $6.8 \pm 0.4 \mathrm{~g} / \mathrm{dL}$ with the onset of CPB (Figure 1). In patients with blood, hemoglobin levels increased markedly during $\mathrm{CPB}$ and reached the preoperative level after retransfusion of the CPB priming volume toward the end of the operation. In contrast, in patients without blood, hemoglobin remained essentially unchanged 
TABLE 1. Patient characteristics and in-hospital outcome

\begin{tabular}{lccc}
\hline & With blood & Without blood & $P$ value \\
\hline $\mathrm{N}$ & 6 & 17 & \\
Age (d) & $8.7 \pm 1.2$ & $9.1 \pm 4.4$ & .807 \\
Size (cm) & $50 \pm 1$ & $51 \pm 3$ & .540 \\
Body weight (kg) & $3.1 \pm 0.4$ & $3.4 \pm 0.6$ & .353 \\
CPB time (min) & $148 \pm 58$ & $120 \pm 21$ & .096 \\
Aortic clamp time (min) & $93 \pm 24$ & $80 \pm 14$ & .123 \\
Postop transfusion & $6(100 \%)$ & $11(65 \%)$ & .144 \\
ICU stay (min) & & & \\
$\quad$ Range & $3-21$ & $1-11$ & .401 \\
$\quad$ Median (25/75) percentiles & $5.5(3.5 / 6.0)$ & $4.0(2.0 / 7.0)$ & \\
Ventilation (h) & & & \\
$\quad$ Range & $26-515$ & $22-167$ & .529 \\
$\quad$ Median (25/75) percentiles & $56(40 / 100)$ & $48(29 / 102)$ & \\
Wound infection & $1(17 \%)$ & $4(24 \%)$ & 1.00 \\
Mortality (30 d) & $1(17 \%)$ & 0 & .261 \\
CRP (mg/100 mL) & $8.6 \pm 4.9$ & $6.5 \pm 4.7$ & .310 \\
\hline
\end{tabular}

Data are means \pm standard deviation or median and 25 and 75 percentiles as appropriate. $\mathrm{CPB}$, Cardiopulmonary bypass; $I C U$, intensive care unit; $C R P$, $\mathrm{C}$-reactive protein. The group of infants without intraoperative blood transfusion was additionally divided into neonates who received postoperative transfusions $(\mathrm{n}=11)$ and those who did not $(n=6)$. There was no major difference in the outcome parameters between these subgroups (data not shown). $P$ values were assessed by $t$ test for normally distributed data, by Mann-Whitney rank sum test for intensive care unit stay and ventilation, and by Fisher's exact test for incidence of postoperative transfusion, wound infection, and 30-day mortality.

during CPB and increased only slightly after termination of $\mathrm{CPB}$ and retransfusion of the priming volume. Thus, at the end of the operation, hemoglobin was significantly higher in patients with blood $(11 \pm 0.5 \mathrm{~g} / \mathrm{dL})$ than without blood $(9.8$ $\pm 0.4 \mathrm{~g} / \mathrm{dL}$ ). CPB flow and oxygen delivery were similar in both groups (Table 3 ).

TABLE 2. In-hospital outcome

\begin{tabular}{lcccc}
\hline & $\begin{array}{c}\text { With } \\
\text { blood }\end{array}$ & $\begin{array}{c}\text { Without blood } \\
\text { (postop blood) }\end{array}$ & $\begin{array}{c}\text { Without } \\
\text { blood }\end{array}$ & $\begin{array}{c}\boldsymbol{P} \\
\text { value }\end{array}$ \\
\hline $\mathrm{N}$ & 6 & 11 & 6 & \\
Postop PRBCs & 4 & 11 & 0 & \\
Postop FFP & 5 & 2 & 0 & \\
$\begin{array}{l}\text { Postop platelets } \\
\text { ICU stay (d) }\end{array}$ & 1 & 0 & 0 & \\
$\quad$ Range & $3-21$ & $2-11$ & $1-9$ & .575 \\
$\quad$ Median (25/75) & $5.5(3.5 / 6.0)$ & $5.0(2.5 / 7.0)$ & $4.0(2.5 / 4.8)$ & \\
$\quad$ percentiles & & & & \\
Ventilation (h) & & & & \\
$\quad$ Range & $26-515$ & $22-167$ & $22-140$ & .772 \\
$\quad$ Median (25/75) & $56(40 / 100)$ & $48(29 / 110)$ & $49(31 / 69)$ & \\
$\quad$ percentiles & & & & \\
Wound infection & $1(17 \%)$ & $2(18 \%)$ & $2(33 \%)$ & .724 \\
Mortality (30 d) & $1(17 \%)$ & 0 & 0 & .227 \\
CRP (mg/100 mL) & $8.6 \pm 4.9$ & $6.7 \pm 5.0$ & $6.2 \pm 4.3$ & .574 \\
\hline
\end{tabular}

Transfusion requirements (FFP, fresh frozen plasma; $P R B C s$, packed red blood cells) are given as numbers of patients who received any of these products for the group with intraoperative transfusion (with blood), the group without intraoperative but with postoperative transfusion (without blood [postop blood]), and the group without any transfusion of homologous blood products (without blood). Outcome data that had already been given in Table 1 are specified for these groups. ICU, Intensive care unit; $C R P$, C-reactive protein.
Blood gas and acid-base data are listed in Table 3. There were no preoperative differences between groups. Onset of CPB terminated the TGA-induced cyanosis in both groups. Arterial oxygen content decreased in both groups with the onset of CPB and remained decreased in neonates in the without blood group until the end of the procedure. Central venous oxygen content at the end of the procedure was decreased only in the without blood group. The $\mathrm{pH}$ was kept unchanged, but base excess decreased more in the group with blood. In both groups, plasma lactate concentration significantly increased during the procedure, but markedly more in patients with blood than in those without blood. Arterial and central venous pressures and body temperature were similar in both groups.

Preoperative cerebral tissue oxygenation was similar in both groups and was significantly increased in patients in the group with blood during CPB (Figure 2). In patients without blood there was also a trend for increased cerebral $\mathrm{rSO}_{2}$, which became statistically significant at the end of CPB. After $\mathrm{CPB}$, cerebral $\mathrm{rSO}_{2}$ returned to preoperative values in both groups. Lower body $\mathrm{rSO}_{2}$ as measured on the calf was also similar before surgery, increased in both groups during $\mathrm{CPB}$, but remained elevated until the end of surgery only in the group of neonates treated without blood (Figure 3).

\section{DISCUSSION}

The major message of this study is that minimizing the $\mathrm{CPB}$ priming volume during cardiac surgery for correction of complex congenital cardiac defects such as TGA reduced the need for blood transfusion even in neonates without jeopardizing tissue oxygenation or patient safety.

Successful attempts to minimize hemodilution and avoid transfusion of homologous blood products in pediatric cardiac surgery have been reported previously. Ootaki and associates ${ }^{16}$ established a criterion-driven transfusion protocol, with hematocrit less than $15 \%$ during CPB and less than $20 \%$ after surgery or a mixed venous oxygen saturation below $50 \%$ as transfusion triggers. Fifty-three $(71 \%)$ of 75 infants could be operated on without blood transfusion. However, the infants in this study had an average age of 3.2 and 7.9 years and a mean body weight of 11.2 and 24.6 $\mathrm{kg}$ in the groups with and without blood transfusion, respectively. Ando and colleagues ${ }^{4}$ introduced a miniaturized CPB circuit with priming volumes of 160 and $130 \mathrm{~mL}$ for children with body weights above and below $4.5 \mathrm{~kg}$, respectively. They report results for 158 consecutive patients who were operated on for repair of ventricular septal defect. The CPB circuit was primed with blood only if hematocrit value was expected to decrease below $15 \%$. Thus, 122 infants were operated on without blood transfusion and only 6 of these received blood transfusion postoperatively. The mean age of the infants without blood was 3.8 months and the mean body weight was $4.3 \mathrm{~kg}$. Kotani and coworkers ${ }^{17}$ reported 


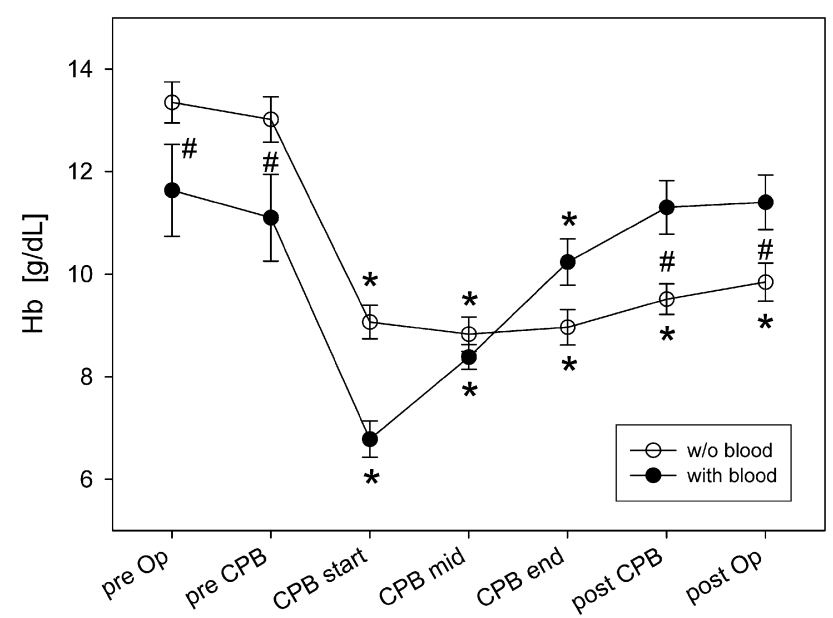

FIGURE 1. The course of blood hemoglobin $(H b)$ concentrations during cardiac surgery is given for neonates without intraoperative blood transfusion (w/o blood) and with blood transfusion (with blood). Means \pm SEM; ${ }^{*} P<.05$ versus pre Op; $\# P<.05$ w/o blood versus with blood. $C P B$, Cardiopulmonary bypass.

their experience with a low priming volume $\mathrm{CPB}$ circuit with $300 \mathrm{~mL}$ or $550 \mathrm{~mL}$ for flow rates below and above $1500 \mathrm{~mL} /$ min, respectively. Of 536 children with body weight greater than $5 \mathrm{~kg}, 264(49 \%)$ were operated on for various congenital cardiac defects without receiving homologous blood products. Transfusion trigger was a hematocrit value less than $20 \%$ for patients with biventricular repair and less than $25 \%$ for patients with single ventricle palliation. Mean age and body weight in the nontransfusion group were 37 months and $12.2 \mathrm{~kg}$, respectively. Miyaji and colleagues ${ }^{18}$ presented a miniaturized CPB circuit with a priming volume of 140 $\mathrm{mL}$, which allowed for blood-free priming for children with a body weight between 4 and $7 \mathrm{~kg}$. Hematocrit value during CPB less than $20 \%$, central venous oxygen saturation less than $70 \%$, brain oxygenation as measured by NIRS less than $50 \%$, and lactate levels greater than $4 \mathrm{mmol} / \mathrm{L}$ were the triggers for blood transfusion. Forty-five (64\%) of 70 infants were operated on without blood transfusion. Mean body weight of the nontransfused group was $5.6 \mathrm{~kg}$.

The present study differs from these previous reports by including only neonates with body weights between 2.7 and $4.2 \mathrm{~kg}$ undergoing the complex surgical procedure of switch operation for TGA. Yet surgery could be completed without blood transfusion in $74 \%$ of cases and in $26 \%$ blood transfusion could be completely avoided. However, also neonates receiving blood transfusion in the ICU may profit from the blood-free completion of CPB because reduction of priming volume has been shown to ameliorate the inflammatory response to pediatric cardiac surgery independently from blood transfusion. ${ }^{19,20}$ In addition, the minimized CPB circuits also reduce dilution of platelets and plasmatic coagulation factors that may result in better preservation of the hemostatic system. ${ }^{9}$
Pivotal for these results is the CPB circuit presented here, which is unique as compared with the circuits discussed above by its very low priming volume of 95 to $110 \mathrm{~mL}$ while maintaining the standard safety features such as arterial line filter. In some of the previous reports, hematocrit value during CPB was allowed to decrease to $15 \%,{ }^{4,16}$ whereas hemoglobin concentration less than $7 \mathrm{~g} / \mathrm{dL}$, corresponding to a hematocrit value of about $21 \%$, was considered a transfusion trigger in the present report. Hemodilution to a hematocrit value of $15 \%$ seemed to be safe in previous reports, ${ }^{4,16}$ but these concerned older children. The possible hazards of hemodilution have to be weighed against the expected benefits of transfusion-free surgical procedures. It is still under debate what the safe hematocrit level for neonates and infants under the conditions of CPB and hypothermia may be. ${ }^{4}$ In anemic preterm infants with hematocrit values less than $25 \%$, blood transfusion increased cerebral, splanchnic, and renal tissue oxygenation. ${ }^{21,22}$ However, tissue oxygenation before transfusion did not indicate tissue hypoxia and it is unclear whether transfusions were well timed to avoid tissue hypoxia or too early and possibly prooxidant. ${ }^{21}$ Several studies reported lower psychomotor development in infants after acute hemodilution during CPB to a hematocrit value less than $22 \%{ }^{23-25}$ during cardiac surgery. In a more recent analysis, a linear correlation between psychomotor development and hematocrit values between $15 \%$ and $23.5 \%$ during low-flow CPB was detected. ${ }^{26}$ That might suggest that the transfusion trigger of hemoglobin less than $7 \mathrm{~g} / \mathrm{dL}$ in the present study could put some patients at risk for cerebral injury. Indeed, 4 infants in our study had a hematocrit value less than $23.5 \%$ for a duration of more than 5 minutes. However, conditions during CPB differ by higher temperature $\left(26^{\circ} \mathrm{C}-28^{\circ} \mathrm{C}\right.$ vs $\left.18^{\circ} \mathrm{C}\right)$ and higher CPB flow $\left(1.7-2.0 \mathrm{~L} \cdot \mathrm{min}^{-1} \cdot \mathrm{m}^{-2}\right.$ vs $\left.0.75 \mathrm{~L} \cdot \mathrm{min}^{-1} \cdot \mathrm{m}^{-2}\right)$ in our protocol. It is unknown how these differences would actually affect cerebral tissue oxygenation and thus postoperative psychomotor development in our patients. In addition, cerebral oxygenation is continuously monitored in our protocol, which we consider an additional safety measure that might help to avoid periods of cerebral hypoxia during CPB.

Most of the previous reports include a mixed patient population with various congenital heart defects including atrial or ventricular septal defects $(50 \%$ of patients in the report by Miyaji and associates ${ }^{18}$ ), which are characterized by short $\mathrm{CPB}$ duration and aortic crossclamp time. Ando, Takahashi, and Suzuki ${ }^{4}$ included only patients undergoing ventricular septal defect repair, and CPB duration and aortic crossclamp times were characteristically short (53 and 31 minutes, respectively). A longer CPB time has been shown to be significantly associated with the need for blood transfusion in infants. ${ }^{3,18}$ The present report includes only neonates undergoing the arterial switch operation for 
TABLE 3. Perioperative oxygenation and hemodynamic data

\begin{tabular}{|c|c|c|c|c|c|c|c|c|}
\hline & Group & Preop & Pre-CPB & CPB start & CPB mid & CPB end & Post-CPB & Postop \\
\hline Blood sample & & Art & C-ven & Art & Art & Art & Art & C-ven \\
\hline \multirow[t]{2}{*}{$\mathrm{Po}_{2}(\mathrm{~mm} \mathrm{Hg})$} & With blood & $60 \pm 9$ & $38 \pm 5$ & $357 \pm 33^{*}$ & $270 \pm 15^{*}$ & $239 \pm 19^{*}$ & $102 \pm 37$ & $31 \pm 2$ \\
\hline & W/o blood & $53 \pm 6$ & $34 \pm 2$ & $336 \pm 21^{*}$ & $261 \pm 16^{*}$ & $244 \pm 18^{*}$ & $99 \pm 14^{*}$ & $29 \pm 1$ \\
\hline \multirow[t]{2}{*}{$\mathrm{So}_{2}(\%)$} & With & $90.7 \pm 2.6$ & $72.9 \pm 4.9$ & $99.8 \pm 0.2 *$ & $99.7 \pm 0.1 *$ & $99.7 \pm 0.1 *$ & $94.3 \pm 1.8$ & $62.7 \pm 3.2$ \\
\hline & W/o & $89.9 \pm 2.0$ & $71.9 \pm 36$ & $99.6 \pm 0.1 *$ & $99.5 \pm 0.1 *$ & $99 . \pm 0.2^{*}$ & $97.4 \pm 0.6^{*}$ & $59.5 \pm 2.7^{*}$ \\
\hline \multirow[t]{2}{*}{$\mathrm{C}-\mathrm{O}_{2}(\mathrm{~mL} / \mathrm{dL})$} & With & $14.8 \pm 1.5$ & $11.5 \pm 1.7$ & $10.1 \pm 0.7^{*}$ & $12.1 \pm 0.5^{*}$ & $14.5 \pm 0.7 *$ & $14.7 \pm 0.7$ & $9.8 \pm 0.7$ \\
\hline & $\mathrm{W} / \mathrm{o}$ & $16.2 \pm 0.6$ & $12.4 \pm 0.8$ & $13.4 \pm 0.4 * \dagger$ & $12.8 \pm 0.5^{*}$ & $12.9 \pm 0.5^{*}$ & $12.8 \pm 0.4^{*}$ & $7.8 \pm 0.5^{*}$ \\
\hline \multirow[t]{2}{*}{$\mathrm{pH}$} & With & $7.43 \pm 0.03$ & $7.40 \pm 0.03$ & $7.38 \pm 0.06$ & $7.39 \pm 0.05$ & $7.40 \pm 0.05$ & $7.41 \pm 0.03$ & $7.37 \pm 0.02$ \\
\hline & $\mathrm{W} / \mathrm{o}$ & $7.48 \pm 0.02$ & $7.44 \pm 0.02$ & $7.42 \pm 0.02$ & $7.40 \pm 0.02$ & $7.43 \pm 0.02$ & $7.44 \pm 0.02$ & $7.37 \pm 0.02$ \\
\hline \multirow[t]{2}{*}{$\mathrm{BE}(\mathrm{mmol} / \mathrm{L})$} & With & $-0.5 \pm 0.8$ & $-0.5 \pm 0.5$ & $-4.4 \pm 1.0^{*}$ & $-4.1 \pm 0.8^{*}$ & $-3.9 \pm 0.7$ & $-3.2 \pm 0.8$ & $-2.4 \pm 0.7$ \\
\hline & $\mathrm{W} / \mathrm{o}$ & $0.5 \pm 0.8$ & $1.2 \pm 0.7$ & $-2.0 \pm 0.6^{*}$ & $-1.7 \pm 0.6^{*}$ & $-0.2 \pm 0.6^{*} \dagger$ & $-0.6 \pm 0.7 * \dagger$ & $-0.6 \pm 0.8^{*}$ \\
\hline \multirow[t]{2}{*}{ Lactate $(\mathrm{mmol} / \mathrm{L})$} & With & $1.4 \pm 0.3$ & $1.8 \pm 0.3$ & $2.0 \pm 0.4$ & $3.6 \pm 0.5^{*}$ & $4.2 \pm 0.6^{*}$ & $4.0 \pm 0.6^{*}$ & $4.1 \pm 0.7^{*}$ \\
\hline & $\mathrm{W} / \mathrm{o}$ & $1.3 \pm 0.1$ & $1.4 \pm 0.1$ & $1.5 \pm 0.2$ & $2.3 \pm 0.2^{*} \dagger$ & $2.4 \pm 0.3 * \dagger$ & $2.4 \pm 0.2 * \dagger$ & $2.4 \pm 0.2^{*} \dagger$ \\
\hline \multirow[t]{2}{*}{ Platelets $(1000 / \mu \mathrm{L})$} & With & $366 \pm 74$ & & & & & & $210 \pm 24$ \\
\hline & $\mathrm{W} / \mathrm{o}$ & $363 \pm 38$ & & & & & & $203 \pm 20^{*}$ \\
\hline \multirow[t]{2}{*}{ Fibrinogen $(\mathrm{mg} / \mathrm{dL})$} & With & $191 \pm 35$ & & & & & & $149 \pm 23$ \\
\hline & W/o & $265 \pm 23$ & & & & & & $127 \pm 9^{*}$ \\
\hline \multirow[t]{2}{*}{ MAP (mm Hg) } & With & $40 \pm 2$ & $31 \pm 1$ & $35 \pm 5$ & $36 \pm 5$ & $49 \pm 3$ & $47 \pm 3$ & $49 \pm 2$ \\
\hline & $\mathrm{W} / \mathrm{o}$ & $42 \pm 2$ & $36 \pm 2$ & $36 \pm 2$ & $42 \pm 3$ & $48 \pm 3$ & $49 \pm 3$ & $49 \pm 3$ \\
\hline \multirow[t]{2}{*}{ CVP $(\mathrm{mm} \mathrm{Hg})$} & With & $8.8 \pm 1.2$ & $7.7 \pm 1.0$ & $4.2 \pm 0.4^{*}$ & $4.2 \pm 2.2^{*}$ & $5.3 \pm 1.4^{*}$ & $7.3 \pm 1.2$ & $6.7 \pm 0.8$ \\
\hline & $\mathrm{W} / \mathrm{o}$ & $7.7 \pm 0.5$ & $6.1 \pm 0.5$ & $4.5 \pm 0.8^{*}$ & $4.7 \pm 0.7^{*}$ & $5.5 \pm 0.6^{*}$ & $8.1 \pm 0.5$ & $7.9 \pm 0.5$ \\
\hline \multirow[t]{2}{*}{ Temp $\left({ }^{\circ} \mathrm{C}\right)$} & With & $33.8 \pm 0.4$ & $32.9 \pm 0$ & $29.9 \pm 1.8^{*}$ & $25.7 \pm 1.5^{*}$ & $35.4 \pm 0.9$ & $35.5 \pm 0.3$ & $35.3 \pm 0.2$ \\
\hline & W/o & $34.4 \pm 0.2$ & $33.0 \pm 0.6$ & $31.4 \pm 0.5^{*}$ & $27.6 \pm 0.3^{*}$ & $34.4 \pm 0.6$ & $35.7 \pm 0.2$ & $35.7 \pm 0.2$ \\
\hline \multirow[t]{2}{*}{ CPB flow $\left(\mathrm{mL} \cdot \mathrm{min}^{-1} \cdot \mathrm{m}^{-2}\right)$} & With & & & $2.5 \pm 0.4$ & $1.7 \pm 0.4^{*}$ & $2.3 \pm 0.2$ & & \\
\hline & W/o & & & $2.5 \pm 0.2$ & $2.0 \pm 0.1^{*}$ & $2.6 \pm 0.2$ & & \\
\hline \multirow[t]{2}{*}{$\mathrm{CPB} \mathrm{O}_{2} \mathrm{D}\left(\mathrm{mL} \cdot \mathrm{min}^{-1} \cdot \mathrm{m}^{-2}\right)$} & With & & & $256 \pm 48$ & $194 \pm 37$ & $326 \pm 29$ & & \\
\hline & $\mathrm{W} / \mathrm{o}$ & & & $340 \pm 25$ & $255 \pm 18^{*}$ & $328 \pm 27$ & & \\
\hline \multirow[t]{2}{*}{$\mathrm{Po}_{2} / \mathrm{FIO}_{2}(\mathrm{~mm} \mathrm{Hg})$} & With & $87 \pm 18$ & & & & & $243 \pm 89 *$ & \\
\hline & W/o & $94 \pm 9$ & & & & & $247 \pm 33^{*}$ & \\
\hline
\end{tabular}

Art, Arterial blood sample; $C$-ven, central venous blood sample; $W / o$, without; $\mathrm{Po}_{2}$, oxygen tension; $\mathrm{So}_{2}$, oxygen saturation; $\mathrm{C}$ - $\mathrm{O}_{2}$, oxygen content; $\mathrm{BE}$, base excess; $M A P$, mean arterial pressure; $\mathrm{CVP}$, central venous pressure; Temp, rectal temperature; $\mathrm{CPB}$, cardiopulmonary bypass; $\mathrm{O}_{2} \mathrm{D}$, oxygen delivery; $\mathrm{Fio} \mathrm{O}_{2}$, inspired gas mixture oxygen fraction. All data are means \pm SEM. $* P<.05$ versus preop. $\dagger P<.05$ versus neonates who received blood, both adjusted $P$ values according to repeated-measures analysis of variance with Holm-Sidak post hoc tests.

repair of TGA. According to the complexity of the procedure, CPB time was much longer (147 and 120 minutes in infants with and without blood, respectively), with a trend for shorter time on CPB in the group without blood $(P=.096)$. In a mixed patient population with greater variability of CPB time, the association between CPB duration and the need for blood may be more pronounced. ${ }^{3,16,18}$ Among others, age, body weight, and preoperative hematocrit value have been identified as predictors for the need of blood transfusion. ${ }^{3,16,18}$ Within the homogeneous patient population of the present study, only preoperative hemoglobin concentration was significantly lower in neonates who required blood transfusion.

In the special population of this study, infants with the cyanotic cardiac defect TGA, arterial oxygen saturation increased with the onset of $\mathrm{CPB}$, which, together with lower oxygen demand owing to hypothermia, more than compensated for the effect of hemodilution on tissue oxygenation. Thus, brain oxygenation increased in both groups during
$\mathrm{CPB}$, indicating good maintenance of cerebral tissue oxygenation despite hemodilution. Lower body oxygenation also increased in both groups, indicating maintenance of oxygenation in peripheral tissues. Lactate concentration moderately increased during CPB in both groups, yet it was significantly more pronounced in the group with blood. This increase can be partly attributed to application of lactate with the transfused red blood cells in the group with blood.

\section{LIMITATION OF THE STUDY}

The major limitation of this report is the small sample size, which precludes definite conclusions about the safety of the proposed protocol. Thus, the observation that no differences among groups concerning in-hospital outcome were detected, such as duration of ventilation and ICU stay or incidence of postoperative complications, neither proves that our protocol to avoid transfusion is safe nor disproves the potential benefits by avoiding transfusion. In addition, the most relevant outcome measure, postoperative 


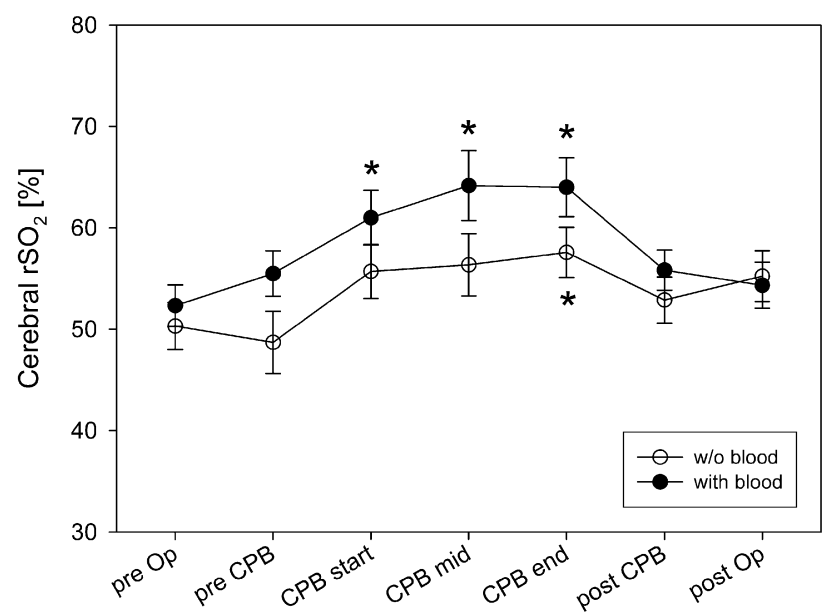

FIGURE 2. Cerebral tissue oxygenation (cerebral $r \mathrm{So}_{2}$ ) as determined by near-infrared spectroscopy during cardiac surgery is given for neonates without intraoperative blood transfusion ( $w /$ o blood) and with blood transfusion (with blood). Means $\pm \mathrm{SEM} ;{ }^{*} P<.05$ versus pre-Op. Differences between groups were not significant. $C P B$, Cardiopulmonary bypass.

mental and psychomotor development, was not assessed at all. However, the goal of this study was to demonstrate how a stringent blood-sparing approach including a very low priming volume $\mathrm{CPB}$ would affect intraoperative hemodilution and the need for transfusion of homologous blood products. Whether this approach has the potential to actually improve outcome and what the safe hematocrit level for this protocol might be have to be evaluated in future studies.

In conclusion, our results indicate that even complex cardiac surgery can be performed in neonates without the need for blood transfusion, at least in a subgroup of infants,

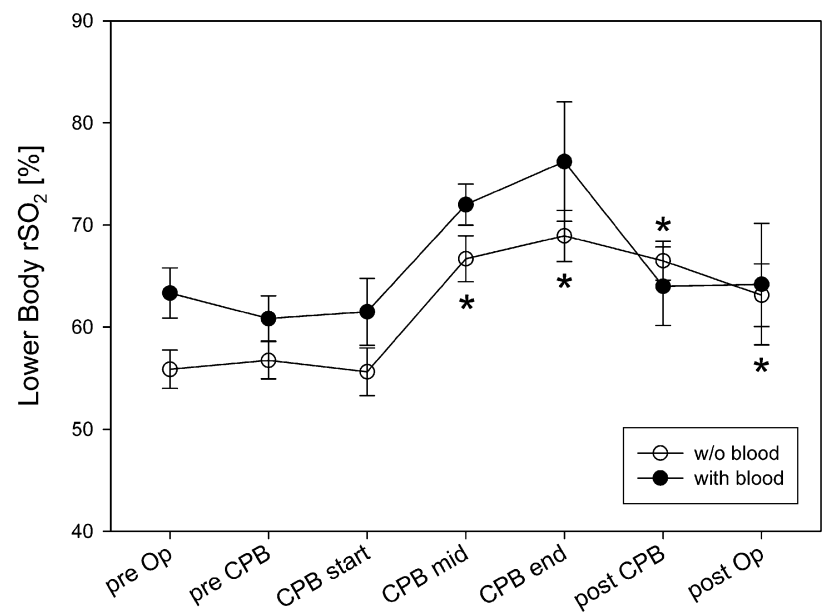

FIGURE 3. Lower body tissue oxygenation (Lower Body $r \mathrm{SO}_{2}$ ) as determined by near-infrared spectroscopy on the infant's calf during cardiac surgery is given for neonates without intraoperative blood transfusion (w/o blood) and with blood transfusion (with blood). Means \pm SEM; ${ }^{*} P<.05$ versus pre-Op. Differences between groups were not significant. $C P B$, Cardiopulmonary bypass. whereas cerebral and peripheral tissue oxygenation as assessed by NIRS is maintained. Preliminary outcome data suggest that despite lower postoperative hemoglobin concentration, the effort to avoid blood transfusion has no hazardous consequences for the infants.

\section{References}

1. Welke KF, Shen I, Ungerleider RM. Current assessment of mortality rates in congenital cardiac surgery. Ann Thorac Surg. 2006;82:164-70.

2. Welke KF, Diggs BS, Karamlou T, Ungerleider RM. Comparison of pediatric cardiac surgical mortality rates from national administrative data to contemporary clinical standards. Ann Thorac Surg. 2009;87:216-22.

3. Szekely A, Cserep Z, Sapi E, Breuer T, Nagy CA, Vargha P, et al. Risks and predictors of blood transfusion in pediatric patients undergoing open heart operations. Ann Thorac Surg. 2009;87:187-97.

4. Ando M, Takahashi Y, Suzuki N. Open heart surgery for small children without homologous blood transfusion by using remote pump head system. Ann Thorac Surg. 2004;78:1717-22.

5. Dodd RY. The risk of transfusion-transmitted infection. N Engl J Med. 1992;327: 419-21.

6. Kuehnert MJ, Roth VR, Haley NR, Gregory KR, Elder KV, Schreiber GB, et al. Transfusion-transmitted bacterial infection in the United States, 1998 through 2000. Transfusion. 2001;41:1493-9.

7. Michalopoulos A, Tzelepis G, Dafni U, Geroulanos S. Determinants of hospital mortality after coronary artery bypass grafting. Chest. 1999;115:1598-603.

8. Engoren MC, Habib RH, Zacharias A, Schwann TA, Riordan CJ, Durham SJ. Effect of blood transfusion on long-term survival after cardiac operation. Ann Thorac Surg. 2002;74:1180-6.

9. Hornykewycz S, Odegard KC, Castro RA, Zurakowski D, Pigula F, DiNardo JA. Hemostatic consequences of a non-fresh or reconstituted whole blood small volume cardiopulmonary bypass prime in neonates and infants. Paediatr Anaesth. 2009; 19:854-61.

10. Koster A, Huebler M, Boettcher W, Redlin M, Berger F, Hetzer R. A new miniaturized cardiopulmonary bypass system reduces transfusion requirements during neonatal cardiac surgery: initial experience in 13 consecutive patients. J Thorac Cardiovasc Surg. 2009;137:1565-8.

11. Redlin M, Koster A, Huebler M, Boettcher W, Nagdyman N, Hetzer R, et al. Regional differences in tissue oxygenation during cardiopulmonary bypass for correction of congenital heart disease in neonates and small infants: relevance of near-infrared spectroscopy. J Thorac Cardiovasc Surg. 2008;136:962-7.

12. Boettcher W, Merkle F, Huebler M, Koster A, Schulz F, Kopitz M, et al. Transfusion-free cardiopulmonary bypass in Jehovah's Witness patients weighing less than 5 kg. J Extra Corpor Technol. 2005;37:282-5.

13. Huebler M, Redlin M, Boettcher W, Koster A, Berger F, Peters B, et al. Transfusion-free arterial switch operation in a $1.7-\mathrm{kg}$ premature neonate using a new miniature cardiopulmonary bypass system. J Card Surg. 2008;23:358-60.

14. Matcher SJ, Cooper CE. Absolute quantification of deoxyhaemoglobin concentration in tissue near infrared spectroscopy. Phys Med Biol. 1994;39: 1295-312.

15. Suzuki S, Takasaki S, Ozaki T, Kobayashi Y. A tissue oxygenation monitor using NIR spatially resolved spectroscopy. Proc SPIE. 1999;3597:582-92.

16. Ootaki Y, Yamaguchi M, Yoshimura N, Oka S, Yoshida M, Hasegawa T. Efficacy of a criterion-driven transfusion protocol in patients having pediatric cardiac surgery. J Thorac Cardiovasc Surg. 2004;127:953-8.

17. Kotani Y, Honjo O, Nakakura M, Fujii Y, Ugaki S, Oshima Y, et al. Single center experience with a low volume priming cardiopulmonary bypass circuit for preventing blood transfusion in infants and small children. ASAIO J. 2009;55: 296-9.

18. Miyaji K, Kohira S, Miyamoto T, Nakashima K, Sato H, Ohara K, et al. Pediatric cardiac surgery without homologous blood transfusion, using a miniaturized bypass system in infants with lower body weight. J Thorac Cardiovasc Surg. 2007; 134:284-9.

19. Miyaji K, Miyamoto T, Kohira S, Inoue N, Itatani K, Sato H, et al. The influences of red blood cell transfusion on perioperative inflammatory responses using a miniaturized biocompatible bypass with an asanguineous prime. Int Heart J. 2009;50:581-9.

20. Fukumura F, Kado H, Imoto Y, Shiokawa Y, Minami K, Murakami J, et al. Usefulness of low-priming-volume cardiopulmonary bypass circuits and dilutional ultrafiltration in neonatal open-heart surgery. J Artif Organs. 2004;7:9-12. 
21. Dani C, Pratesi S, Fontanelli G, Barp J, Bertini G. Blood transfusions increase cerebral, splanchnic, and renal oxygenation in anemic preterm infants. Transfusion. 2010;50:1220-6.

22. Bailey SM, Hendricks-Munoz KD, Wells JT, Mally P. Packed red blood cell transfusion increases regional cerebral and splanchnic tissue oxygen saturation in anemic symptomatic preterm infants. Am J Perinatol. 2010;27:445-53.

23. Jonas RA, Wypij D, Roth SJ, Bellinger DC, Visconti KJ, du Plessis AJ, et al. The influence of hemodilution on outcome after hypothermic cardiopulmonary bypass: results of a randomized trial in infants. J Thorac Cardiovasc Surg. 2003; 126:1765-74
24. Limperopoulos C, Majnemer A, Shevell MI, Rosenblatt B, Rohlicek C, Tchervenkov C. Neurologic status of newborns with congenital heart defects before open heart surgery. Pediatrics. 1999;103:402-8.

25. Limperopoulos C, Majnemer A, Shevell MI, Rosenblatt B, Rohlicek C Tchervenkov C. Neurodevelopmental status of newborns and infants with congenital heart defects before and after open heart surgery. J Pediatr. 2000;137:638-45

26. Wypij D, Jonas RA, Bellinger DC, del Nido PJ, Mayer JE Jr, Bacha EA, et al. The effect of hematocrit during hypothermic cardiopulmonary bypass in infant heart surgery: results from the combined Boston hematocrit trials. J Thorac Cardiovasc Surg. 2008;135:355-60. 